\title{
ANALISA ELECTRONIC WORD OF MOUTH (E-WOM) PADA MEDIA SOSIAL TWITTER
}

\author{
Heribertus Yulianton ${ }^{1}$, Felix Andreas Sutanto ${ }^{2}$, Kristophorus Hadiono ${ }^{3}$ \\ ${ }^{1,2,3}$ Fakultas Teknologi Informasi, Universitas Stikubank \\ Email: ${ }^{1}$ heribertus@gmail.com, ${ }^{2}$ felix @ unisbank.ac.id, ${ }^{3}$ kris@ unisbank.ac.id
}

\begin{abstract}
Abstrak
E-WOM adalah pernyataan positif atau negatif yang dibuat oleh konsumen potensial, konsumen aktual, dan konsumen terdahulu tentang produk atau perusahaan melalui internet. Salah satu media yang dapat digunakan untuk mendapatkan pernyataan tersebut adalah media sosial twitter. Media sosial dapat digunakan untuk mendapatkan respon secara jujur karena biasanya orang tidak akan merasa sungkan untuk mengungkapkan perasaannya secara tidak langsung.

Penelitian ini akan menganalisa ada atau tidaknya pernyataan e-WOM terhadap penyedia jasa layanan internet. Metode yang dilakukan terdiri dari tiga kegiatan, yang pertama adalah mengambil cuitan pengguna twitter yang mengandung kata yang berhubungan dengan penyedia jasa layanan internet. Kegiatan kedua adalah persiapan data untuk training. Yang ketiga adalah menganalisa e-wom dengan metode knn dan bahasa pemrograman R.

Hasil penelitian ini berupa data motif e-wom Venting Negative Feelings dan Extraversion / Positive Self-Enhancement. Data tersebut dapat digunakan sebagai pendukung keputusan pengguna internet dalam memilih penyedia jasa layanan internet yang baik.
\end{abstract}

Kata kunci: e-wom, twitter, provider, inernet.

\section{PENDAHULUAN}

\section{a. Pendahuluan}

Dalam dunia bisnis, Word of Mouth (WoM) adalah media yang paling kuat dalam mengomunikasikan produk atau jasa kepada konsumen. Word of Mouth adalah tindakan yang dilakukan konsumen untuk memberikan informasi kepada konsumen lain secara non komersial mengenai merek, produk maupun jasa. (Hasan, 2010). Konsumen yang telah memiliki pengalaman unik tentang produk, jasa, dan merek dari perusahaan tertentu, cenderung akan memasukkan produk, jasa, dan merek tersebut ke agenda percakapan. Mereka secara sadar atau tanpa sadar mengungkapkannya kepada orang lain secara lisan (word of mouth) dalam berbagai kesempatan. Seiring dengan perkembangan Internet, saat ini WoM telah berkembang menjadi electronic word-ofmouth. Menurut Hennig- Thurau (2004), electronic Word of Mouth (e-WoM) communication merujuk pada pernyataan positif atau negatif dari pelanggan potensial, pelanggan aktual atau mantan pelanggan mengenai suatu produk atau perusahaan via internet.

Pada saat ini metode pemasaran lewat website bukanlah hal yang asing bagi pengguna internet. Hal ini bisa dilihat dengan munculnya website-website UMKM yang bisa ditemukan lewat mesin pencari seperti google, bing, yahoo dan sebagainya. Namun tidak semua UMKM bisa berhasil dalam usaha ini karena websitenya mungkin tidak memiliki pengunjung, kalah bersaing di posisi mesin pencari atau kualitas produknya tidak ada yang merekomendasi. Dalam, hal pemasaran online telah dikenal istilah Content Management System (CMS) dan Search Engine Optimation (SEO). Kedua metode tersebut juga telah diterapkan untuk e-commerce toko online UMKM (Sutanto, 2015). Namun penerapannya hanya menghasilkan posisi pada halaman pertama mesin pencari dan belum membahas tentang pengaruhnya terhadap pembelian produk. Oleh karena itu perlu dicari cara agar pemasaran yang dilakukan dapat mempengaruhi pembelian produk.

Penelitian ini akan menganalisa percakapan yang dapat dikategorikan sebagai electronic Word of Mouth pada media sosial twitter. Untuk mendapatkan data dari twitter akan mengunakan bahasa $\mathrm{R}$ 
yang telah menyediakan library untuk mengaksesnya. Media sosial Twitter dipilih karena media ini memungkinkan penggunanya untuk memberikan komentar atau tanggapan tentang suatu produk secara bebas baik itu mendukung atau mengkritiknya. Ujaran dari seorang pengguna twitter berpotensi memperluas pangsa pasar maupun mencegah konsumen untuk membeli produk atau layanan suatu perusahaan.

\section{b. Perumusan Masalah}

Berdasarkan latar belakang yang telah dikemukakan sebelumnya, dapat dirumuskan masalah sebagai berikut:

1) Mendapatkan tweet dari media sosial Twitter dan menentukan kata yang dapat dikategorikan sebagai Electronic Word of Mouth (E-Wom).

2) Menganalisa percakapan pada media sosial Twitter yang dapat dikategorikan sebagai Electronic Word of Mouth (E-Wom).

\section{TUJUAN DAN MANFAAT PENELITIAN}

\section{a. Tujuan Penelitian}

Tujuan khusus penelitian ini adalah sebagai berikut:

1) Melakukan identifikasi dan analisis motif-motif E-Wom yang ada pada media sosial Twitter.

2) Mengetahui motif yang paling banyak dilakukan oleh pengguna media sosial Twitter.

\section{b. Manfaat Penelitian}

Adapun manfaat dari penelitian ini adalah membantu vendor untuk mendapatkan respon dari masyarakat tentang produknya. Sekaligus dapat memberikan gambaran tentang cara memasarkan produknya di internet melalui metode e-WOM.

\section{TELAAH PUSTAKA}

\section{a. Penelitian Yang Telah Dilakukan}

Henning-Thurau, dkk. (2004) dalam penelitiannya mengemukakan bahwa Electronic Word of Mouth (EWOM) berisi pernyataan positif atau negatif yang dibuat oleh konsumen potensial, konsumen aktual, dan konsumen terdahulu tentang produk atau perusahaan melalui internet. Konsumen mendapatkan mendapatkan informasi dari konsumen lain yang telah menggunakan produk melalui EWOM.

Penelitian tentang rancang bangun portal E-Commerce produk handicraft menggunakan metode object oriented programming. Portal ini dibangun untuk mengembangkan pemasaran pada UMKM Handicraft. Untuk memudahkan pengisian konten portal digunakan metode Content Management System (CMS). Object oriented programming diterapkan pada saat implementasi aplikasinya (Galih, 2011).

Model Cyber Cluster Partisipatif dalam usaha memasarkan secara online produk unggulan UMKM dapat digunakan untuk memasarkan produk- produk UMKM secara efektif, mudah dan cepat disasar oleh konsumen. Cara ini membutuhkan peran aktif dari pelaku UMKM dan masyarakat untuk membuat link website. Hal tersebut perlu dilakukan secara masif agar website tersebut dapat berada pada halaman pertama mesin pencari internet (Diartono, 2012).

Media yang paling banyak digunakan sebagai media e-WoM yaitu situs jaringan sosial seperti Facebook, Twitter, MySpace, Friendster, Foursquare, dll.

Orang-orang yang bergabung dalam salah satu komunitas jaringan sosial tersebut saling berbagi pengalaman dan pengetahuan mengenai berbagai macam hal. Penerapan EWOM pada media sosial Foursquare mengungkapkan adanya perbedaan tipe pengguna yang mempengaruhi mereka dalam memberikan suatu pernyataan mengenai suatu produk atau jasa. Untuk memanfaatkan kekuatan dari electronic Word of Mouth (e-WoM), perusahaan harus terlebih dahulu mengidentifikasi dan mengerti pengguna web secara efektif untuk menyebarkan pendapat mereka. (Rita dkk, 2013) 
Mengacu pada penelitian yang telah dilakukan, penelitian ini akan menganalisa faktor-faktor yang mempengaruhi pembelian produk UMKM dan membuat model sistem electronic word of mouth berbasis media sosial.

\section{b. Motif E-Wom}

Menurut Thurau et al. (2004), E-Wom memiliki motif sebagai berikut:

1) Platform assistance: kepercayaan konsumen terhadap platform yang digunakan. Perilaku eWOM dapat dilihat melalui frekuensi kunjungan dan jumlah komentar ditulis oleh konsumen pada opinion platform.

2) Venting negative feelings: keinginan mengungkapkan ketidakpuasan konsumen terhadap produk atau perusahaan. Upaya ini dilakukan dalam bentuk eWOM negatif, yaitu jika pelanggan mengalami hal yang tidak menyenangkan atau negatif bagi mereka. Komunikasi eWOM dilakukan untuk mencegah orang lain mendapat pengalaman yang sama seperti yang pernah mereka alami.

3) Concern for other consumers: keinginan memberikan rekomendasi kepada konsumen lain. Konsumen memiliki keinginan untuk membantu konsumen lain terkait dengan keputusan pembelian. Komunikasi ini dapat berbentuk komentar positif dan negatif tentang produk.

4) Extraversion/positive self-enhancement: keinginan konsumen berbagi pengalaman konsumsi mereka untuk meningkatkan citra diri sebagai pembeli yang cerdas. Dalam konteks website, konsumen yang berkontribusi dianggap lebih ahli oleh konsumen lain dalam aktivitas konsumsi produk tersebut.

5) Social benefits: keinginan berbagi informasi dan berinteraksi dengan lingkungan sosial. Konsumen dapat menulis komentar pada opinion platform, yang menandakan partisipasi mereka dalam komunitas virtual. Dengan partisipasi tersebut, konsumen merasa mendapatkan manfaat atau keuntungan sosial jika bergabung dalam komunitas virtual.

6) Economic incentives: keinginan memperoleh insentif dari perusahaan. Manfaat ekonomi telah ditunjuk sebagai pendorong penting dari perilaku manusia secara umum dan dianggap oleh penerima sebagai tanda penghargaan terhadap perilaku komunikasi eWOM.

7) Helping the company: keinginan konsumen membantu perusahaan. Motif inimuncul hasil dari kepuasan konsumen terhadap produk dan memunculkan keinginan untuk membantu perusahaan yang bersangkutan.

8) Advice seeking: keinginan mencari saran dan rekomendasi dari konsumen lain. Motif melakukannya adalah untuk mendapatkan pemahaman lebih lanjut bagaimana memahami, menggunakan, mengoperasikan, memodifikasi, dan/atau memperbaiki produk.

\section{c. Bahasa Pemrograman $\mathbf{R}$}

$\mathrm{R}$ bukan saja bahasa tetapi juga lingkungan/environment untuk komputasi statistik dan grafik. $\mathrm{R}$ merupakan project GNU yang dikembangkan oleh Bell Laboratories (sebelumnya AT\&T, sekarang Lucent Technologies). Team pengembang $\mathrm{R}$ adalah John Chamber dan teman-temannya. $\mathrm{R}$ menyediakan berbagai macam tool statistik dari linier dan memodelan non linier, uji statistik klasik, analisis time-series, klasifikasi, clustering dan lain-lain. $\mathrm{R}$ juga menyediakan tool teknik grafis yang bertujuan untuk menampilkan data yang telah diolah secara visual dalam bentuk grafik. R merupakan project open-source yang memungkinkan banyak pihak untuk memberikan kontribusi dalam proses pengembangan.

Default lingkungan $\mathrm{R}$ telah memiliki banyak fungsi-fungsi yang dapat digunakan untuk berbagai keperluan. Lingkungan R dapat ditambahkan fungsi- fungsi baru. Fungsi-fungsi baru tersebut biasanya dalam bentuk package. Fungsi- fungsi package hanya dapat digunakan jika package telah dimuat. Package harus dimuat setiap saat session baru dibuat atau setiap saat baru menjalankan tool pemrograman R. Fungsi untuk memuat package adalah library(). Sintaks fungsi ini adalah sebagai berikut:

library(NamaPackage) atau library("NamaPackage")

Berikut adalah contoh kode untuk memuat package "kernlab".

library("kernlab") 
Working directory atau direktori kerja adalah direktori/folder aktif pada suatu session. User hanya dapat mengakses file script $\mathrm{R}$ dan file data yang berada pada working direktory. Jika user ingin mengakses file di luar working directory maka user harus menulis path direktori/folder dan nama file. Untuk menentukan working directory dapat digunakan fungsi setwd(). Sintaks fungsi ini adalah sebagai berikut:

setwd("path_absolute")

Kode di bawah ini adalah contoh penggunaan fungsi setwd() dan outputnya.

$>\operatorname{setwd}(" C: / ")$

$>\operatorname{getwd}()[1] " C: / "$

Format file yang umum digunakan untuk menyimpan data adalah file text yang berisi nilai-nilai yang dipisahkan oleh tanda koma atau tab. File Excel juga umum digunakan untuk menyimpan data. Untuk membaca file Excel diperlukan package "xslx". Platform R juga dapat membaca data dari database server seperti MySQL dan SQL Server.

\section{d. Media Sosial Twitter}

Twitter adalah situs web dimiliki dan dioperasikan oleh Twitter, Inc., yang menawarkan jaringan sosial berupa microblog dan media sosial. Disebut microblog karena situs ini memungkinkan penggunanya mengirim dan membaca pesan blog seperti pada umumnya namun terbatas hanya sejumlah 140 karakter yang ditampilkan pada halaman profil pengguna. Twitter memiliki karakteristik dan format penulisan yang unik dengan simbol ataupun aturan khusus. Pesan dalam Twitter dikenal dengan sebutan tweet. (L. Zhang, 2011).

Untuk mengetahui isu-isu terhangat didunia, Twitter telah menyediakan trending topic yang mencerminkan topik populer yang biasanya ditandai dengan tanda tagar (\#). Ada 2 jenis Topik Hangat (Trending Topic) yang menjadi acuan pengguna di Indonesia, yaitu Topik Hangat Seantero Dunia (Trending Topic World Wide / TTWW) dan Topik Hangat Indonesia (Trending Topic Indonesia / TTI), kemudian yang terjadi di Indonesia khususnya terutamanya adalah karena hal-hal yang sedang banyak peminatnya pada saat itu. Twitter juga telah menyediakan API untuk developer yang membutuhkan data. Untuk menggunakannya dapat dilakukan dengan cara sebagai berikut:

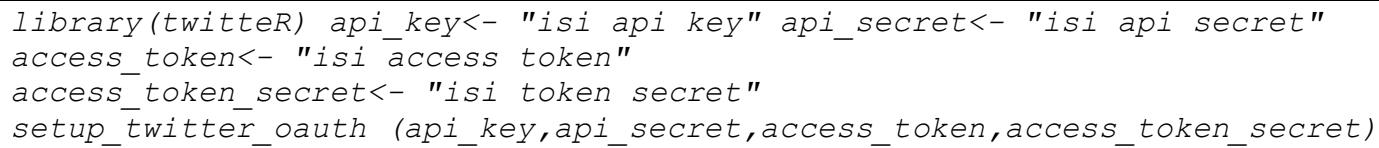

\section{e. Machine Learning}

Machine learning adalah bidang yang mempelajari pengembangan algoritma komputer untuk mengubah data menjadi aksi yang cerdas atau secara singkat dapat juga diartikan sebagai proses mengubah data menjadi informasi. Untuk membuat data menjadi domain model agar didapat informasi yang dapat digunakan untuk melakukan aksi maka digunakan metode-metode yang telah dikenal pada bidang statistik. Proses data dengan metode-metode statistik tersebut dibantu dengan bantuan kekuatan komputasi yang dimiliki oleh komputer. Karena menggunakan metode statistik maka proses di atas disebut statistical learning, tetapi lebih populer atau lebih dikenal dengan istilah machine learning.

Machine learning dapat dibedakan menjadi dua tipe. Tipe yang dimaksudkan di sini adalah tipe algoritma yaitu:

1) Supervised learning.

2) Unsupervised learning.

Supervised Learning adalah pembelajaran yang telah diketahui apa yang akan diprediksi atau target variablenya. Sehingga tujuan membangun algoritma sudah jelas hal apa yang akan diprediksi. Oleh karena itu model yang dihasilkan dari tipe ini adalah model prediksi. Model prediksi digunakan untuk melakukan proses prediksi target variable (target feature) berdasarkan feature-feature lain pada suatu dataset. Algoritma pembelajaran yang dibangun mencoba untuk menemukan dan memodelkan hubungan antara target variable (target feature) tersebut dengan feature-feature lainnya. Klasifikasi 
adalah contoh task mechine learning tipe supervised untuk melakukan prediksi. Beberapa contoh penerapan klasifikasi adalah sebagai berikut:

1) Penentuan email adalah email spam.

2) Penentuan seseorang mengidap kanker.

3) Penentuan kemenangan suatu tim sepakbola.

Unsupervised Learning merupakan kebalikan dari tipe sebelumnya dimana tidak terdapat target variable (target feature) pada dataset. Model yang dihasilkan dari tipe ini adalah descriptive model. Salah satu task descriptive model untuk menemukan pola yang bisa mengidentifikasi asosiasi pada dataset. Contoh implementasinya dapat dilakukan pada menemukan pola pada proses analisis barang yang dibeli oleh pembeli pada suatu super market atau mini market. Tujuan dari analisis ini adalah untuk mengetahui barang-barang yang sering dibeli bersama-sama. Sebagai contoh jika pembeli membeli roti maka otomatis juga membeli keju dan susu kental manis. Atau jika pembeli membeli sabun cuci maka juga membeli pengharum pakaian. Dengan informasi pola tersebut maka pemilik super market dapat menggunakannya untuk membuat iklan diskon untuk kelompok barang tersebut, atau pemilik juga dapat membuat agar tata letak barang-barang tersebut dibuat berdekatan. (Reza Faisal, 2016)

\section{METODE PENELITIAN}

\section{a. Metode Pengumpulan Data}

Metode pengumpulan data yang dilakukan pada penelitian ini meliputi:

1) Observasi

Observasi dilakukan di Universitas Stikubank Semarang untuk mendapatkan data di media sosial twitter.

2) Studi Kepustakaan

Studi kepustakaan dilakukan untuk memperoleh literatur-literatur yang relevan dengan obyek penelitian.

\section{b. Metode Analisa dan Perancangan}

Dalam penelitian ini, metode yang digunakan untuk analisa dan perancangan meliputi :

1) Analisis

Pada tahap ini dicari alternatif-alternatif pemecahan masalah yang paling sesuai untuk mengatasi permasalahan yang ada.

2) Desain

Merancang pemecahan masalah untuk menentukan langkah-langkah operasi, prosedur, sekaligus membuat desain secara menyeluruh yang meliputi data dan prosedur dan algoritma pemrograman.

3) Implementasi

Implementasi algoritma yang telah dibuat, sesuai dengan spesifikasi yang telah ditentukan dalam desain.

4) Testing

Setelah program selesai dibuat maka tahap selanjutnya adalah menguji coba program.

\section{HASIL DAN PEMBAHASAN}

\section{a. Langkah Penelitian}

Penelitian ini akan menganalisa ada atau tidaknya e-WOM pada media sosial Twitter. Sosial media Twitter dipilih karena media ini adalah salah satu yang banyak penggunanya. Selain itu Twitter adalah media sosial yang berbasis teks, sehingga memungkinkan eksplorasi yang lebih luas tentang suatu topik.

Langkah pertama yang akan dilakukan adalah menentukan topik percakapan apa saja yang akan dicari dalam media sosial Twitter. Pada penelitian ini topik ditentukan berdasarkan motif e-WOM yang dianggap sesuai dengan kondisi pada media sosial. Langkah kedua adalah mencari tweet yang 
sesuai dengan topik yang telah ditentukan. Untuk mendapatkan data tersebut digunakan bahasa $\mathrm{R}$ yang dilengkapi dengan library untuk mengakses media sosial Twitter.

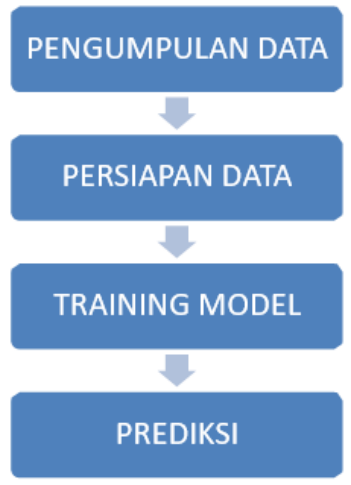

Gambar 1. Langkah Penelitian

Langkah ketiga adalah melakukan klasifikasi terhadap data tersebut sesuai dengan motif e-WOM yang telah ditentukan sebelumnya. Klasifikasi dilakukan dengan cara membandingkan kalimat tweet dengan daftar kata yang telah ditentukan dalam motif e-WOM. Jika tweet yang didapat sesuai dengan daftar kata yang ada pada motif, maka bisa disimpulkan bahwa tweet tersebut merupakan bagian dari electronic-Word of Mouth.

\subsection{Motif e-WOM}

Penelitian ini bertujuan untuk menganalisa tweet yang diposting oleh pengguna Twitter sehubungan dengan kesan mereka terhadap produk IndiHome. Untuk mendapatkan tweet yang berhubungan dengan motif E-WOM, disusun daftar sebagai berikut:

\begin{tabular}{|c|c|c|c|}
\hline No & Motif EWOM & Kontek Kalimat & Kata \\
\hline 1 & $\begin{array}{l}\text { Venting Negative } \\
\text { Feelings }\end{array}$ & $\begin{array}{l}\text { Review dari pengguna } \\
\text { IndiHome di internet } \\
\text { menunjukkan } \\
\text { ketidakpuasan }\end{array}$ & $\begin{array}{l}\text { acak } \\
\text { acak-acakan } \\
\text { acuh } \\
\text { acuh tak acuh } \\
\text { bercacat } \\
\text { berdalih } \\
\text { berlebihan } \\
\text { bermasalah } \\
\text { fatal fiksi fitnah jelek } \\
\text { jempol kebawah jengkel } \\
\text { jerat kacau kadaluarsa kesal kesalahan }\end{array}$ \\
\hline 2 & $\begin{array}{l}\text { Extraversion / Positive } \\
\text { Self-Enhancement }\end{array}$ & $\begin{array}{l}\text { Melalui internet } \\
\text { mendapatkan informasi } \\
\text { mengenai pengalaman } \\
\text { positif konsumen } \\
\text { pengguna } \\
\text { IndiHome } \\
\text { Melalui internet } \\
\text { mendapatkan informasi } \\
\text { bahwa IndiHome } \\
\text { merupakan pilihan yang } \\
\text { tepat }\end{array}$ & $\begin{array}{l}\text { agung } \\
\text { ahli } \\
\text { ahlinya } \\
\text { ajaib } \\
\text { akomodatif } \\
\text { akurat } \\
\text { alhamdulillah } \\
\text { bagus } \\
\text { bahagia } \\
\text { baik } \\
\text { berguna } \\
\text { berharga } \\
\text { berhasil } \\
\text { cemerlang } \\
\text { cepat } \\
\text { inovasi }\end{array}$ \\
\hline
\end{tabular}




\begin{tabular}{|l|l|l|}
\hline & $\begin{array}{l}\text { inovatif } \\
\text { inspirasi } \\
\text { inspirasional } \\
\text { inspiratif }\end{array}$ \\
\hline
\end{tabular}

\section{b. Pengumpulan Data}

Pada penelitian ini telah ditentukan penyedia jasa layanan internet yang akan diteliti adalah IndiHome. Data mengenai kesan pengguna terhadap IndiHome didapat dari media sosial Twitter. Sebagai sampel data, dilakukan pencarian data pada tanggal $1-7$ November 2017. Diambil secara acak sebanyak 500 tweet dan data disimpan dalam bentuk Microsoft Excel untuk kemudahan penyajian informasi.

Untuk pengolahan digunakan bahasa $\mathrm{R}$ yang telah menyediakan library untuk mendapatkan data dari Twitter yaitu library twitteR. Penggunaannya seperti pada gambar 2.

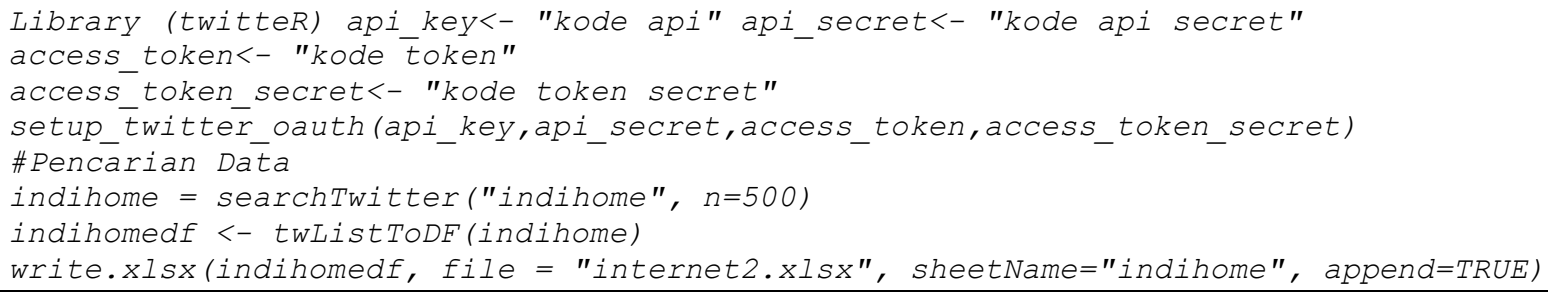

\section{Gambar 2. Pencarian Data Twitter}

Untuk mendapatkan data komentar pengguna twitter, pada penelitian ini dilakukan dalam dua langkah. Langkah pertama adalah mendapatkan kode-kode untuk mengakses data dari twiter. Untuk mendapatkannya diharuskan memiliki account twitter terlebih dahulu, kemudian mengambil kode-kode tersebut melalui web twitter developer.

Langkah kedua adalah menggunakan fungsi searchTwitter() untuk mencari data yang diinginkan. Pencarian dilakukan dengan metode pencarian tweet yang mengandung kata isp pada penelitian ini, yaitu indihome, biznet dan myrepublic. Data yang diperoleh pada saat pencarian bertipe list pada bahasa $\mathrm{R}$, untuk dapat disimpan kedalam Excel, format list harus diubah terlebih dahulu dengan format data frame, setelah itu disimpan ke file excel. Library yang digunakan untuk menyimpan data ke excel adalah library xlsx. Hasil pencarian data dapat dilihat seperti pada gambar 3.

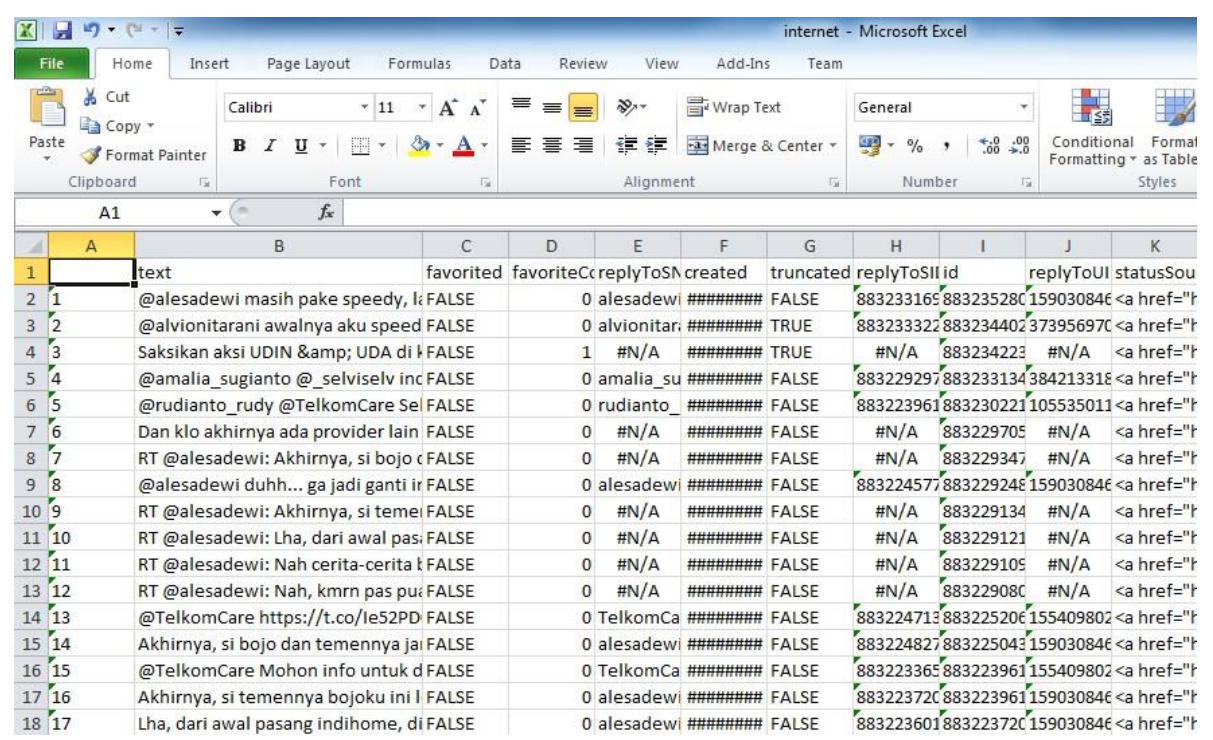

Gambar 3. Hasil Pencarian Data 
Pada saat pencarian, library twitteR mengambil data tidak hanya komentar saja, melainkan juga nama pengguna, reply, retweet, tanggal pembuatan, lokasi dan sebagainya. Sedangkan hal yang diperlukan sebenarnya hanyalah field text saja. Oleh karena itu, pada penelitian ini hal pertama yang dilakukan pada tahap ini adalah mengambil text saja.

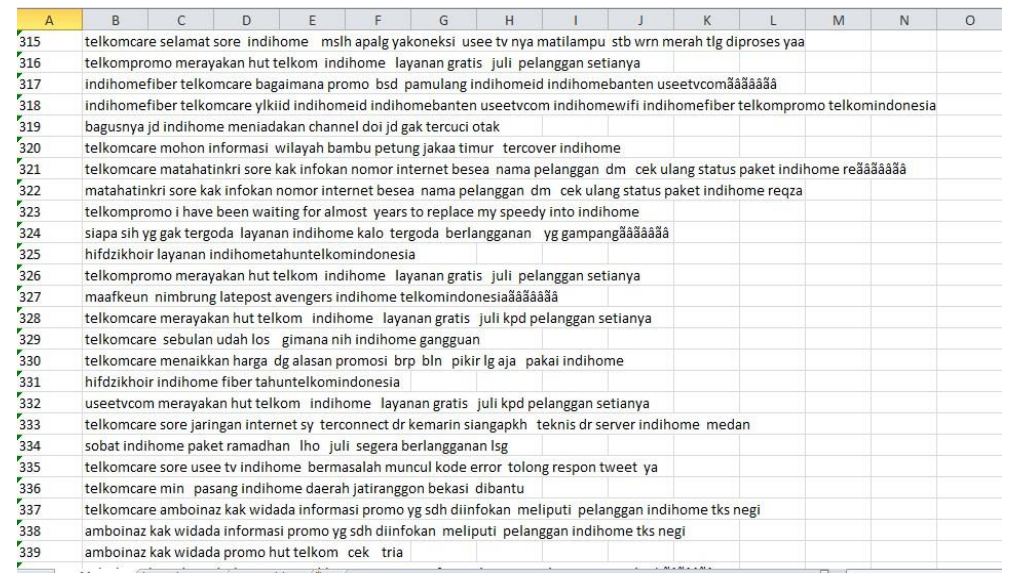

Gambar 4. Hasil Text

Ekstraksi fitur diperlukan agar kata-kata yang akan diprediksi sentimennya efektif. Dalam bahasa indonesia juga dikenal kata-kata yang tidak memiliki makna atau tidak penting yang umumnya disebut stopword. Penghilangan stopword dilakukan berbasis daftar stopword yang dibuat Tala dengan penambahan kata yang tidak baku dalam bahasa indonesia yang juga tidak penting. Contoh daftar kata yang dimasukkan dalam daftar stopword adalah sebagai berikut:

ada

adalah

adanya

adapun

agak

agaknya

agar

akan

akankah

$\mathrm{sbb}$

\section{c. Persiapan Data}

Persiapan data dilakukan dengan cara membuat data yang akan digunakan untuk training dan testing. Persiapan data dilakukan dengan memilih sample sebanyak 20 tweet dengan mengkategorikan motif positif dan negatif serta memberikan hasil apakah kalimat tweet tersebut merupakan motif eWOM Positive Self-Enhancement atau Venting Negative Feelings dengan memberi nilai, , 1" atau „ " 0 . Hasil dari langkah ini dapat dilihat seperti gambar 5. 


\begin{tabular}{|l|l|l|l|}
\hline 1 x & $\mathrm{m} 1$ & $\mathrm{~m} 2$ & \\
\hline 2 & sobat indihome paket ramadhan lho ju & 0 & 0 \\
\hline 3 & alesadewi pake speedy cari ganti smpt & 1 & 0 \\
\hline 4 & alvionitarani speedytrs indihome spee & 1 & 0 \\
\hline 5 & saksikan aksi udin uda kompetisi indiho & 0 & 0 \\
\hline 6 & amaliasugianto selviselv indihome ihhh & 1 & 0 \\
\hline 7 rudiantorudy telkomcare selamat siang k & 0 & 0 \\
\hline 8 & dan klo provider yg masuk jogja suam & 0 & 0 \\
\hline 9 & alesadewi duhh ga ganti indihome deh & 1 & 0 \\
\hline 10 & telkomcare mohon info daftar harga ind & 0 & 0 \\
\hline 11 akhirnya si temennya bojoku telepon k & 0 & 0 \\
\hline 12 & telkompromo untung indihome ada beb & 0 & 0 \\
\hline 13 & saya suka video youtube cara bobol indi & 0 & 1 \\
\hline 14 & kak nomor telepon memanggil teknisi i & 0 & 0 \\
\hline 15 & rayindra karna ultah telkom kl yaa chann & 0 & 0 \\
\hline 16 & kini dgn hybrid box tambahan hdk sobat & 0 & 0 \\
\hline 17 hallo warga jatiasih jika keluhan info pe & 1 & 0 \\
\hline 18 & halo sobat indihome kini menikmati ta' & 0 & 1 \\
\hline 19 & telkomsel males banget nonton hp kuot & 1 & 0 \\
\hline 20 & indihome segera masuk karimun telkom & 0 & 0 \\
\hline
\end{tabular}

Gambar 5. Persiapan Data

\section{d. Training Model}

Data training disusun berdasarkan hasil persiapan data. Pada tahap ini peneliti melakukan analisa terhadap tweet untuk memberikan hasil apakah kalimat tweet tersebut merupakan e-WOM atau bukan. Penentuannya e-WOM atau bukan dengan memberi nilai „, $\mathrm{Y}^{\mathrm{ec}}$ untuk kondisi benar dan „T"e untuk kondisi yang salah. Hasil dari langkah ini dapat dilihat seperti gambar 6.

\begin{tabular}{|c|c|c|c|}
\hline 1 & $\mathrm{x}$ & $\mathrm{m} 1$ & resul \\
\hline 2 & sobat indihome paket ramadhan Iho ju & 0 & $0 y$ \\
\hline 3 & alesadewi pake speedy cari ganti smpt & 1 & $0 \mathrm{t}$ \\
\hline 4 & alvionitarani speedytrs indihome spee & 1 & $0 \mathrm{y}$ \\
\hline 5 & saksikan aksi udin uda kompetisi indiho & 0 & $0 \mathrm{t}$ \\
\hline 6 & amaliasugianto selviselv indihome inhh & 1 & $0 \mathrm{y}$ \\
\hline 7 & rudiantorudy telkomcare selamat siang $\mathrm{k}$ & 0 & $0 \mathrm{t}$ \\
\hline 8 & dan klo provider yg masuk jogja suam & 0 & $0 \mathrm{t}$ \\
\hline 9 & alesadewi duhh ga ganti indihome deh & 1 & $0 y$ \\
\hline 10 & telkomcare mohon info daftar harga ind & 0 & $0 \mathrm{t}$ \\
\hline 11 & akhirnya si temennya bojoku telepon $\mathrm{k}$ & 0 & $0 \mathrm{y}$ \\
\hline 12 & telkompromo untung indihome ada beb & 0 & $0 \mathrm{t}$ \\
\hline 13 & saya suka video youtube cara bobol indi & 0 & $1 \mathrm{t}$ \\
\hline 14 & kak nomor telepon memanggil teknisi t & 0 & $0 t$ \\
\hline 15 & rayindra karna ultah telkom kl yaa chann & 0 & $0 y$ \\
\hline 16 & kini dgn hybrid box tambahan hdk sobat & 0 & $0 \mathrm{t}$ \\
\hline 17 & hallo warga jatiasih jika keluhan info pe & 1 & $0 y$ \\
\hline 18 & halo sobat indihome kini menikmati ta' & 0 & $1 \mathrm{y}$ \\
\hline 19 & telkomsel males banget nonton hp kuot & 1 & $0 y$ \\
\hline 20 & indihome segera masuk karimun telkom & 0 & $0 y$ \\
\hline
\end{tabular}

Gambar 6. Data Training

\section{e. Prediksi}

Klasifikasi adalah salah satu teknik machine learning. Teknik ini termasuk ke dalam tipe supervised learning. Istilah klasifikasi didapat dari tujuan utama teknik ini untuk memprediksi sebuah kategori dari input data. Sebelum melakukan proses prediksi, terlebih dahulu dilakukan proses pembelajaran. Proses pembelajaran memerlukan data. Data yang digunakan pada proses pembelajaran disebut data latih atau data training. Sedangkan data yang digunakan pada proses predeksi disebut data uji atau data testing. 
Data yang digunakan untuk training dapat ditunjukkan pada tabel sebagai berikut:

\begin{tabular}{|c|c|c|c|}
\hline Tweet & m1 & $\mathbf{m} 2$ & result \\
\hline sobat indihome paket ramadhan lho juli segera berlangganan lsg & 0 & 0 & $\mathrm{~T}$ \\
\hline alesadewi pake speedy cari ganti smpt ganti indihome tp liat gini jd ga hehe & 1 & 0 & $\mathrm{Y}$ \\
\hline alvionitarani speedytrs indihome speedy versi pake fiber optic hebat & 0 & 1 & $\mathrm{Y}$ \\
\hline saksikan aksi udin uda kompetisi indihome grass roots festival jumat juli minggu juli & 0 & 0 & $\mathrm{~T}$ \\
\hline amaliasugianto selviselv indihome ihhh malesin bgt & 1 & 0 & $\mathrm{Y}$ \\
\hline rudiantorudy telkomcare selamat siang bapak indihome dikecepatan mbps bapak tksyr & 0 & 0 & $\mathrm{~T}$ \\
\hline dan klo provider yg masuk jogja suami secepat kilat pindah ganti indihome sih & 1 & 1 & $\bar{Y}$ \\
\hline alesadewi duhh ga ganti indihome deh kalo gitu & 1 & 0 & $\mathrm{Y}$ \\
\hline telkomcare mohon info daftar harga indihome bisnis & 0 & 0 & $\mathrm{~T}$ \\
\hline akhirnya si temennya bojoku telepon konfirmasi telkom indihome tepatnya dapetlah penjelasan & 0 & 1 & $\mathrm{Y}$ \\
\hline $\begin{array}{l}\text { telkompromo untung indihome ada bebas tlp menit bersilatuhrahmi mau coba yuk berlangganan } \\
\text { indihome }\end{array}$ & 0 & 0 & $\mathrm{~T}$ \\
\hline saya suka video youtube cara bobol indihome work by pendi & 0 & 1 & $\mathrm{Y}$ \\
\hline kak nomor telepon memanggil teknisi memperbaiki indihome ya telkomcare & 0 & 0 & $\mathrm{~T}$ \\
\hline rayindra karna ultah telkom kl yaa channel indihome kebuka sampe kpn min telkomcare & 0 & 0 & $\mathrm{~T}$ \\
\hline kini dgn hybrid box tambahan hdk sobat merasakan pengalaman sma tv & 0 & 1 & $\mathrm{Y}$ \\
\hline $\begin{array}{l}\text { hallo warga jatiasih jika keluhan info pemasangan indihome langsung cek twitter ya } \\
\text { infojatiasih }\end{array}$ & 0 & 1 & $\mathrm{Y}$ \\
\hline halo sobat indihome kini menikmati tayangan channel useetvcom dgn kualitas gambar yg lebih & 0 & 1 & $\mathrm{Y}$ \\
\hline telkomsel males banget nonton hp kuota terbuang yg indihome aja gak ketonton & 1 & 0 & Y \\
\hline indihome segera masuk karimun telkom gelar kabel laut batam karimun & 0 & 0 & $\mathrm{~T}$ \\
\hline Indihome sangat bagus di daerah saya kecepatan maksimal & 0 & 1 & $\mathrm{Y}$ \\
\hline
\end{tabular}

Algoritma K-Nearest Neighbors memprediksi kategori instance baru berdasarkan informasi dari instance-instance terdekat dengannya atau tetangga terdekatnya. Algoritma ini hanya dapat digunakan jika data yang digunakan mempunyai feature-feature bernilai numerik. Data dengan feature bernilai numerik digunakan untuk menentukan jarak antara instance baru dengan instance pada data training. Ada beberapa teknik yang dapat digunakan untuk menghitung jarak, salah satunya adalah euclidean distance.

Implementasi algoritma KNN pada lingkungan R dapat dilakukan dengan menggunakan fungsi knn() dan kknn(). Fungsi knn() adalah bagian dari package class. Package ini telah tersedia pada lingkungan R. Sedangkan fungsi kknn() adalah bagian dari package kknn. Langkah pertama sebelum menggunakan fungsi ini adalah menginstall package kknn. Berikut ini adalah fungsi yang digunakan untuk menggunakan package kknn:

\section{kknn(formula, train, test, $k$, distance, kernel)}

Keterangan:

1) formula: formula untuk menentukan target variable.

2) train: data training.

3) test: data testing.

4) k: jumlah tetangga.

5) distance: parameter untuk Minkowski distance.

6) kernel: nama kernel atau fungsi yang digunakan.

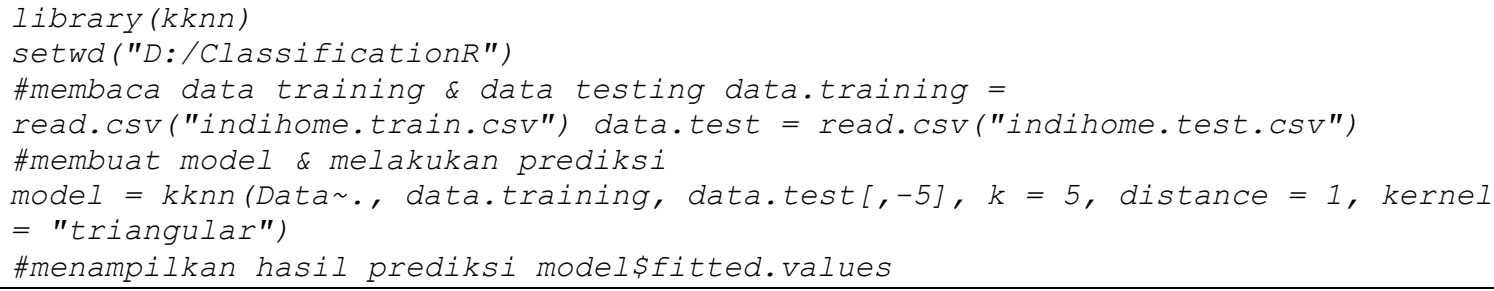

Obyek model adalah output dari fungsi kknn(). Sehingga obyek ini menyimpan nilai-nilai hasil perhitungan dari fungsi kknn(). Nilai-nilai pada obyek ini adalah:

1) fitted.values berisi daftar class yang merupakan hasil prediksi untuk setiap instance.

2) CL adalah matrix yang berisi class dari instance tetangga terdekat. 
3) W adalah matrix yang berisi nilai bobot dengan instance tetangga terdekat.

4) D adalah matrix yang berisi nilai jarak dengan instance tetangga terdekat.

5) $\mathrm{C}$ adalah matrix yang berisi index dari instance tetangga terdekat.

6) prob adalah matrix yang berisi kemungkinan (probabilitas) prediksi terhadap suatu class.

Untuk mengetahui ketepatan hasil prediksi maka nilai di atas dapat dibandingkan dengan nilai class sebenarnya dari setiap instance. Berikut adalah cara untuk membandingkan kedua nilai tersebut:

comparation_result $=$ cbind $($ prediction $=$ as.character $($ model\$fitted .values $)$, actual as.character(data.test [,5]))

print(comparation_result)

Hasil prediksi adalah sebagai berikut:

actual prediction

[1,] "T" "T"

[2,] " $Y$ " " $Y$ "

[3,] " $Y^{\prime \prime} " Y^{\prime \prime}$

[4,] "T" " $T$ "

[5,] " $Y^{\prime \prime} " Y^{\prime \prime}$

[6,] "T" " $T$ "

[7,] " $Y^{\prime \prime} " T^{\prime \prime}$

$[8$,$] " Y$ " " $Y^{\prime \prime}$

$[9$,$] " T$ " "Y"

[10,] " $Y$ " "Y"

[11,] "T" "Y"

[12,] " $Y$ " "Y"

[13,] " $T$ " "T"

[14,] " $T$ " " $T$ "

[15,] " $Y$ " " $Y$ "

[16,] " $Y$ " " $Y$ "

[17,] " $Y$ " " $Y$ "

[18,] " $Y$ " " $Y$ "

[19,] " $T$ " "T"

[20,] " $Y$ " "T"

Dari 20 data training dan data test 20 data juga, diperoleh hasil prediksi yang salah sebanyak 5 data. Sehingga prosentasi keberhasilan adalah $15 / 20$ yaitu $75 \%$.

\section{KESIMPULAN DAN SARAN}

\section{a. Kesimpulan}

Kesimpulan dari penelitian ini adalah:

1) Opini pengguna jasa layanan internet dapat diperoleh dari media sosial twitter.

2) Hasil query tweet isinya ditentukan oleh pengguna twitter, tidak bisa dikondisikan sesuai keinginan peneliti.

3) Stopword perlu penambahan kata yang tidak baku.

4) Penggunaan sistem kamus dapat digunakan untuk opini mining, tetapi keakuratan sangat bergantung pada isi kamus.

\section{b. Saran}

Saran yang bisa diberikan untuk penelitian lebih lanjut adalah:

1) Melengkapi kamus perbendaharaan kata yang tidak baku, karena pengguna twitter mungkin menyingkat atau menggunakan istilah dalam bahasa daerah.

2) Menggunakan machine learning sebagai alternatif dalam memprediksi sentimen pengguna twitter terhadap penyedia jasa layanan internet. 


\section{DAFTAR PUSTAKA}

[1] Diartono, DA, 2012, Membangun Model Cyber Cluster Partisipatif Dalam Usaha Memasarkan Secara Online Produk Unggulan UMKM Dan Menarik Investor Di Kabupaten Kendal, Hibah Bersaing, DIKTI.

[2] Galih, ST, dkk., 2011, Rancang Bangun Portal E-Commerce Semarang Handycraft Berorientasi Obyek, Thesis, Magister Sistem Informasi, UNDIP. Hasan, A, 2010, Marketing dari Mulut ke Mulut. MedPress, Yogyakarta

[3] Hennig-Thurau, T., Gwinner, K. P., Walsh, G. and Gremler, D.D. 2004. Electronic word-of-mouth via consumer-opinion platforms: what motivates consumers to articulate themselves on the Internet? Journal of Interactive Marketing. Vol. 18 No. 1 2004: 38-52.

[4] Rita, Karyana Hutomo dan Natalia, 2013, Electronic Word Of Mouth (E-Wom) Foursquare: The New Social Media, Binus Business Review Vol. 4 No. 2 November 2013: 711-724 